\title{
LEITURA LITERÁRIA NO CICLO 1 DO ENSINO FUNDAMENTAL: $O$ LIVRO DIDÁTICO COMO DEFLAGRADOR DE LEITORES PRECÁRIOS
}

\author{
Sheila Oliveira Lima
}

\begin{abstract}
RESUMO
A política para formação do leitor no Brasil conta, entre outros, com a distribuição de livros didáticos de língua materna para escolas públicas de todo o país. Tais materiais veiculam metodologias de abordagem da leitura ineficazes para a formação do leitor em sua fase inicial, conforme aponta estudo realizado entre 2013 e 2015 com os dois primeiros volumes de dez coleçôes didáticas de Língua Portuguesa.
\end{abstract}

PALAVRAS-CHAVE: leitura; literatura; livro didático.

Leitura do texto literário no ciclo 1 do ensino fundamental: perspectivas teóricas e situações reais
1
o longo dos últimos vinte anos, estudiosos do ensino da língua ma- terna e da leitura têm se posicionado de maneira bastante crítica a respeito dos livros didáticos (LD) de língua portuguesa e da dimen- são que tomaram na definição dos currículos e mesmo das metodologias do ensino de leitura.
Lajolo (1999), ao estudar a história da leitura no Brasil, refere-se ao LD como o "primo rico" das editoras, uma vez que há um mercado pronto a assimilá-lo, dadas as deficiências na formação dos profissionais da educação básica. Segundo a autora, a aposta no LD parece gerar um ciclo empobrecedor da formação leitora, na medida em que, no Brasil, desde fins do século XIX, sequestra-se do professor a responsabilidade e mesmo o direito de definir o 
ensino da leitura a partir do seu conhecimento da literatura e, sobretudo, da sua experiência enquanto leitor.

Marcuschi, também na década de 1990, foi taxativo ao afirmar que os LD de Língua Portuguesa eram precários, sobretudo no que concerne ao exercício da leitura. Conforme Marcuschi (1996), as atividades de leitura presentes nos LD por ele analisados não passavam de exercícios de "copiação" dos enunciados presentes nos textos propostos.

Tal precariedade foi, anos depois, novamente observada por Pinheiro (2005). Segundo o estudioso, os LD mantinham atividades de leitura que em nada contribuíam para a formação do leitor, na medida em que subvalorizavam o texto, ao proporem atividades que se restringiam ao reconhecimento de aspectos formais ou que limitavam a leitura ao estrato mais literal do texto.

Mais recentemente, Geraldi (2015) reafirmou ser o LD um dos principais instrumentos para a realização do que denomina como "exercício da capatazia”. Isto é, para o pesquisador, o livro didático, ao trazer conteúdos e metodologias definidos pelas editoras, destitui o professor do seu lugar de mediador entre o aluno e o conhecimento, pois "o professor já não se define mais por saber o saber produzido pelos outros, que organiza e transmite didaticamente a seus alunos, mas se define como aquele que aplica um conjunto de técnicas de controle na sala de aula”. (GERALDI, 2015, p. 86)

O estudo por nós proposto teve como um de seus propósitos verificar o quanto da situação observada em anos anteriores ainda vigora nos LD atuais, sobretudo após o final da década de 1990, quando o PNLD foi amplamente propagado pelo Governo Federal como segura referência para a escolha das coleçôes didáticas pelos professores e pelas escolas.

O projeto "Leitura literária no Ensino Fundamental - Ciclo 1: concepções e práticas", finalizado em dezembro de 2015, teve como objetivo investigar a quantidade e a qualidade das atividades de leitura do texto literário nos primeiros anos do Ensino Básico. Para tanto, elegeram-se como corpora da pesquisa os dois primeiros volumes de dez coleçôes didáticas de língua portuguesa, sendo sete delas recomendadas pelo Programa Nacional do Livro Didático-2012 e três não constantes da lista. Porém, destas últimas, duas são edições similares àquelas submetidas ao PNLD-2012. Justifica-se o hibridismo da lista tendo-se em vista a diversificação dos corpora e a possibilidade de publicação (e consequente adoção pelas escolas) de LD que não tenham participado do edital do PNLD. 
Entendemos que a formação leitora principia desde antes do processo de alfabetização. Entretanto, estamos convencidos de que o contato com a literatura no momento inaugural da criança com o mundo letrado, quando começa a vislumbrar certa autonomia em relação à escrita, é definidor do seu lugar enquanto leitora. Longe do texto literário, das fissuras que ele propóe, corre-se o risco da formação de meros decodificadores, submissos aos discursos injuntivos, próprios dos textos que hoje proliferam nos LD: receitas, manuais de instruçôes, bulas, anúncios publicitários e toda sorte de literatura moralizante e doutrinária. Ao que tudo indica, o que se tem veiculado como atividade leitora, em seu momento inaugural, refere-se tão somente a um processo de ingestão de enunciados, sem a menor possibilidade de questionamentos, já que os textos propostos condicionam a uma leitura sem qualquer chance de interpretação, dúvidas, vazios interpretativos. Trata-se, portanto, de uma formação leitora para as necessidades do presente: servir ao mercado, obedecendo aos apelos da publicidade, sem a necessidade ou a expectativa de questionamentos. $\mathrm{O}$ texto é fechado e a leitura também.

Numa perspectiva educacional mais libertária, porém, lançamos mão do argumento de Ortega y Gasset (1993, p. 26) quando afirma que:

la educación, sobre todo en su primera etapa, en vez de adaptar el hombre ao medio, tiene que adaptarl el medio al hombre; en lugar de apresurarse a convertirnos en instrumentos eficaces para tales o cuales formas transitorias de la civilización, deve fomentar con desinterés y sin prejuícios el tono vital primogenio de nuestra personalidad.

A formação leitora deve ser compreendida como um elemento fulcral na constituição dos indivíduos, na medida em que deverá fazer parte de toda sua vida, expandindo-se sempre que possível ou necessário. Os alicerces constituídos na formação inicial do leitor - fundados desde antes da sua experiência com a alfabetização, e, a partir desta, vigorosamente reforçados - deverão permanecer por todo o seu percurso de letramento. $\mathrm{O}$ ato inaugural da leitura autônoma tende a ser definidor da postura do leitor, desenvolvida, posteriormente, ao longo de toda a sua vida de estudante e mesmo para além dela. Prova disso são as estatísticas que denunciam a ausência de atividade lei- 
tora em adultos após a finalização do percurso escolar, seja no nível básico ou no superior, talvez como resultado do pouco sentido dado à atividade leitora dentro do espaço escolar. Isto é, lia-se porque a escola assim o determinava, para responder perguntas, para fazer trabalhos, para preencher tarefas. Nada mais. Não havendo a demanda escolar, o sujeito, fora da escola, não encontra motivos para a leitura.

Ao contrário do que durante muito tempo se estabeleceu como regra para a leitura escolar, temos a convicção de que o ato de ler, em seu verdadeiro sentido, deverá conduzir o sujeito ao questionamento, à dúvida, à revisão de si e do seu entorno. Por essa razão, não deverá ser instrumento nem instrumentalizador, não podendo se restringir aos textos do mundo burocrático, da vida prática. E é nesse viés que a literatura passa a ser fundamental: porque, conforme Candido (1995, p. 244), "trazendo livremente em si o que chamamos o bem e o que chamamos o mal, humaniza em sentido profundo, porque faz viver.".

Ao fazer tal afirmação, Candido voltava-se para o direito de todo ser humano ao acesso à literatura, como a tantos outros bens culturais. Para nós, além disso, a literatura possibilita um modo de interação com os mais diversos discursos, nas mais diferentes formulaçóes, de um modo mais implicado, porque tocado pela subjetividade. E, nesse sentido, passa a ser extremamente relevante para o processo de aprendizagem da leitura.

Aprender a ler com literatura pode posicionar o leitor de modo a estar atento às formulaçóes ardilosas, aos jogos sintático-semânticos, às matrizes argumentativas de que, em geral, somos vítimas quando não as questionamos. O leitor de literatura revive e descobre angústias, restaura e reinstaura seu lugar na sociedade pela convivência com os mais diversos dramas, táo comuns a todos nós. Ele relê o que não entende. Retoma, questiona, aguarda o desfecho da obra antes de anunciar sua apreciação. E tende a levar todo esse cabedal de experiências para a leitura dos textos da vida cotidiana, orais, escritos, jornalísticos, publicitários, legais, científicos etc.

Sabemos, entretanto, que a leitura do texto literário na escola não é algo que tem sido realizado com tanta facilidade. Talvez, nas séries iniciais do Ensino Fundamental, porém, ela possa ser mais imediatamente apreciada, dada a proximidade da criança com os gêneros narrativo e lírico, próprios da literatura oral infantil e mesmo pelas ediçóes de livros infantis extremamente atraentes hoje em dia. 
Nos LD voltados para os primeiros anos do Ensino Básico, porém, a literatura que surge vem, em geral, demarcada pela necessidade de atuar no processo de alfabetização e nas temáticas transversais, ligadas, em sua maioria, à formação do cidadão. Cumpre, deste modo, um lugar burocrático, perdendo sua autenticidade.

No que se refere ao investimento na alfabetização por meio da literatura, Bettelheim e Zelan (1986), em pesquisa realizada com crianças em fase de alfabetização nos Estados Unidos, constataram que as dificuldades para a aprendizagem da leitura naquele contexto referiam-se, principalmente, à pouca disposição das crianças em lidar com os textos de pouca complexidade que compunham o material didático. Sob o argumento de levar ao estudante elementos já conhecidos, os textos selecionados caracterizavam-se por pobreza vocabular, repetição excessiva de palavras, reiteração de enunciados. Tal situação identificada nos materiais analisados por Bettelheim e Zelan eram a causa do desinteresse pela leitura e, consequentemente, da lentidão na apropriação do código alfabético.

Essa pesquisa vai ao encontro do que vemos hoje no Brasil, tanto no que se refere aos LD quanto aos efeitos de lentificação no período de alfabetização e ao posterior desinteresse pela leitura ao longo de todo o Ensino Básico. Nesse sentido, torna-se elucidativa ao nosso estudo a constatação de Bettelheim e Zelan (1986, p. 49) sobre a realidade estadunidense de então:

Enseñamos a leer a los niños con la esperanza de que lo que lean en el futuro tenga un significado para ellos. Es muy poco probable que una habilidad que no tenía un significado intrínseco cuando la aprendimos por primera vez se vuelva profundamente significativa más adelante, sobre todo al compararla con una actividad que cautivó los estratos más hondos de nuestro ser desde un buen principio.

Para que a atividade leitora se afirme de modo significativo, parece necessário, portanto, que ela seja autêntica, legítima, desde os primeiros contatos autônomos da criança com o texto.

Colomer (2007) identifica que, apesar das dificuldades próprias de cada contexto, é perfeitamente possível formar leitores do texto literário na escola, 
desde os primeiros anos do Ensino Básico. Segundo a pesquisadora, para que tal tarefa se torne realidade, uma das principais ações deve ser a criação de uma comunidade leitora dentro do espaço escolar. Para isso, um fator é indispensável: o compartilhamento.

Em seus estudos sobre o ensino de literatura e a formação do leitor pela escola, Colomer chama a atenção para o sucesso de vendas e de leituras de certas séries populares (como Harry Potter, Ladrão de raios etc.) e aponta para o fato de se tratar de grandes comunidades de sujeitos que compartilham entre si suas leituras. Tais grupos se engajam na leitura não apenas pela pouca complexidade dos textos, mas pelo prazer de fazer parte de um tipo de coletivo envolvido num mesmo fazer, numa mesma busca.

A leitura do texto literário na escola, para Colomer, deveria assimilar um pouco dessa atitude por meio da ampliação "de rotinas de construção compartilhada”. Essas rotinas, para nós, não têm condiçóes de serem implementadas, se a atividade com a literatura ficar restrita a poucos, fragmentados e mal elaborados textos e se forem realizadas por meio de questionários cujas respostas são facilmente depreendidas dos enunciados, sem qualquer tipo de reflexão ou de troca de impressóes entre os leitores em formação.

Em síntese, será impossível formar comunidades leitoras, se o desejo não estiver em causa. E isso só tem condiçôes de ocorrer, na medida em que a leitura passe a ser uma atividade descolada do livro didático, do seu controle absoluto sobre a seleçáo e a (sub)interpretação dos textos.

Dramaticamente, os LD de Língua Portuguesa avaliados em nossa pesquisa não propóem atividades que rumem para a construção de comunidades leitoras no espaço escolar. Os poucos textos em versos ou de ficção em prosa - o que não quer dizer, necessariamente que se trate de literatura - são utilizados, em sua maioria, como instrumento para a apropriação do código alfabético. Ao lado disso, as raras atividades que propóem uma leitura para além do código mantêm o leitor isolado, além de conduzi-lo para uma apreensão literal do texto, mesmo quando se trata de literatura. 


\section{Das impressões aos fatos: resultados da pesquisa com livros didáticos}

$\mathrm{Na}$ pesquisa realizada, as análises das coleçôes didáticas de língua portuguesa foram efetuadas por uma equipe composta por dez membros, sendo seis graduandos de Letras e um de Psicologia, dois mestrandos e dois professores doutores, todos da Universidade Estadual de Londrina.

As primeiras investigaçóes foram quantitativas e buscaram conhecer a proporção de textos literários e não literários presentes nas coleções, computando conjuntamente os volumes 1 e 2 . Tendo em vista, porém, que a qualidade dos textos que poderiam ser tomados por literários foi identificada, muitas vezes, como bastante questionável, definiu-se novo parâmetro, mais relativo aos contextos de circulação que à estrutura. Sendo assim, foram criadas as categorias: (a) textos da esfera literária - versos, prosa ficcional de toda ordem, teatro, quadrinhos, parlendas, adivinhas, trava-línguas, entre outros - e (b) textos da esfera do cotidiano - receitas, notícias, avisos, convites, cartas, envelopes, listas, manual de instrução etc. Desta primeira aferição, observou-se certo equilíbrio entre as quantidades de textos de cada uma das esferas, sendo $50,86 \%$ da literária e $49,13 \%$ da do cotidiano.

Quando separados por série, os números sofrem leve alteração. Os livros do $1^{\circ}$ ano apresentam uma média de $53,06 \%$ de textos da esfera literária e $46,93 \%$ da esfera do cotidiano. Já no $2^{\circ}$ ano, ocorre uma inversão - 48,94\% são da esfera literária e $51,05 \%$ da esfera do cotidiano - o que pode ser o indicativo de uma opção pedagógica que valorize certa relação mais operacional com a escrita e a leitura, sobretudo porque essa alteração resulta da diminuição significativa de textos oriundos da oralidade poética nos livros do $2^{\circ}$ ano.

Com o objetivo de melhor delimitar a esfera literária, foram selecionados apenas os textos oriundos da tradição escrita como corpus a ser analisado. Deste modo, todos os textos inscritos na oralidade, em geral tratados com foco na alfabetização e apresentados completos, foram excluídos da investigação. $\mathrm{O}$ recorte justifica-se pela tentativa de orientar a pesquisa direcionando-a para a formação do leitor da obra literária veiculada por meio do registro escrito, que caracteriza o que se convencionou chamar de literatura.

Dentro do campo da escrita, um fator relevante observado refere-se à apresentação dos textos da esfera literária nos LD: 


\begin{tabular}{|l|c|c|}
\cline { 2 - 3 } \multicolumn{1}{c|}{} & $\mathbf{1}^{\mathbf{0}}$ ano & $\mathbf{2}^{\mathbf{o}}$ ano \\
\hline Textos integrais & $72,19 \%$ & $61,06 \%$ \\
\hline Fragmentos de texto & $27,81 \%$ & $38,93 \%$ \\
\hline Textos originais & $86,69 \%$ & $87,71 \%$ \\
\hline Adaptaçóes & $13,30 \%$ & $12,28 \%$ \\
\hline
\end{tabular}

Tabela 1: Distribuição dos textos pelas características de apresentação.

Esses resultados também são influenciados pelo fato de haver uma quantidade significativa de textos de curta extensão e pouca complexidade, o que permite apresentá-los integrais e na forma original. Os textos que seriam, originalmente, mais complexos, como os contos de fadas tradicionais e certos poemas de autores reconhecidos, surgem adaptados ou em fragmentos que impossibilitam uma leitura significativa.

Nos dados relativos à distribuição dos textos da esfera literária em diversificação de gêneros, observam-se proporçôes bastante díspares, sendo o gênero poema o de maior ocorrência nos livros das duas séries estudadas:

\begin{tabular}{|l|c|c|}
\cline { 2 - 3 } \multicolumn{1}{c|}{} & $\mathbf{1}^{\mathbf{0}}$ ano & $\mathbf{2}^{\mathbf{o}}$ ano \\
\hline Poema & $69,25 \%$ & $57,5 \%$ \\
\hline Prosa & $20,49 \%$ & $33,24 \%$ \\
\hline Teatro & $1,24 \%$ & $0,76 \%$ \\
\hline Quadrinhos & $9 \%$ & $8,43 \%$ \\
\hline
\end{tabular}

Tabela 2: Distribuição em gêneros.

Os dados acima indicam o que já foi, no passado, uma tendência dos LD na Espanha, conforme Colomer (2007): o gênero poema assume um lugar de destaque. Esse fato, infelizmente, parece firmar-se não pela possível riqueza polissêmica ou formal dos exemplares do gênero, mas pela sua pequena extensão, facilitadora de atividades que visem a uma leitura autônoma do alfabetizando, ainda que restrita à decodificação. Essa constatação pode ser confirmada quando se observa que os percentuais relativos aos gêneros em prosa são muito inferiores. Mais ainda, nos LD do $2^{\circ}$ ano, quando se espera que a criança já domine mais amplamente o código alfabético, 
observa-se uma significativa ampliação da quantidade de ocorrências dos textos em prosa.

Outro aspecto que chama a atenção é o ínfimo percentual de textos teatrais, sobretudo se comparado ao dos quadrinhos. Tal fato parece ter como possível justificativa a familiaridade da criança com os quadrinhos, enquanto o acesso ao teatro ainda é uma realidade distante da maioria delas. No entanto, esse mesmo argumento poderia ser usado para justificar a ampliação dos textos teatrais nos LD, na medida em que, inacessíveis para a maioria da população (infantil ou adulta), cabe à escola aproximar tais objetos culturais do estudante, visando a uma formação mais plena.

Tanto para o $1^{\circ}$ quanto para o $2^{\circ}$ ano, observa-se que há uma forte tendência à utilizaçáo do texto da esfera literária como pretexto para abordagem do código alfabético, da caracterização de gêneros textuais, da produção textual e da reflexão sobre proposiçôes morais revestidas de temáticas transversais. Tais atividades focalizam, primordialmente, aspectos formais do texto, não realizando ou realizando de modo superficial a compreensão dos mesmos.

No $1^{\circ}$ ano, as propostas que fazem uso do texto como pretexto totalizam $57,6 \%$ do conjunto de atividades orientadas com gêneros da esfera literária, distribuídas conforme mostra o quadro a seguir:

\begin{tabular}{|l|l|}
\hline Objetivo da atividade & Percentual nos LDs \\
\hline Código alfabético & $41 \%$ \\
\hline Caracterização de gênero & $6,1 \%$ \\
\hline Produção textual & $5,5 \%$ \\
\hline Reflexão temática & $5 \%$ \\
\hline
\end{tabular}

Tabela 3: Percentual de propostas com instrumentalização dos textos literários nos primeiros volumes das coleçôes didáticas.

Considerando que, no $1^{\circ}$ ano do Ensino Fundamental, o foco principal é a alfabetização, parece plenamente justificável um percentual tão alto de dedicação ao desenvolvimento de tal habilidade. Entretanto, é preciso também ponderar que as atividades com texto literário representam uma parcela de todas as propostas no LD, havendo muitos outros textos cujas atividades destinam-se igualmente à alfabetização. Além disso, o percentual indicado refere-se 
a abordagens unicamente relativas ao código, sem qualquer orientação para o aproveitamento do texto enquanto literatura, isto é, para a fruição, reflexão e, mais adiante, humanização.

A exemplo desse fenômeno, apresentamos a seguir a reprodução de uma sequência de atividades presentes no volume 1 da coleção didática Lingua Portuguesa, relativas à canção "O pato", de Vinícius de Moraes:

\section{CONVERSANDO SOBRE O TEXTO}

1) Pinte no texto as palavras que o seu professor ditar. (Os alunos devem trabalhar em duplas. Ditar algumas palavras (pato, papo, jenipapo, tigela, panela, marreco), uma de cada vez, para que os alunos marquem essas palavras no texto com lápis colorido. $)^{1}$

2) Complete as palavras do texto "O pato". (Se necessário, os alunos poderão usar a letra da música, das páginas 88 e 89, para consulta.)

(M) (A) R R (E) () ()

$\mathrm{G}(\underline{\mathrm{A}})(\mathrm{L})(\mathrm{I}) \underline{(\mathrm{N})}(\mathrm{H}) \mathrm{A}$

$\mathrm{P} \underline{(\mathrm{A})} \mathrm{T}(\mathrm{E})(\mathrm{T}) \underline{(\mathrm{A})}$

(C) (A) V (A) (L) O

3.Procure no quadro ${ }^{2}$ as seguintes palavras:

PATO - CAVALO - GALINHA - MARRECO - GALO

4. Destaque, dos adesivos, as tiras e cole a letra da música na ordem certa. ${ }^{3}$

(CARLINI, 2008, p.90-91)

1 Os textos entre parênteses referem-se às orientaçóes ao professor, não constando do LD do aluno. Foram aqui reproduzidas para que fiquem claros os objetivos da atividade e a tendência metodológica no ensino da leitura.

2 A atividade apresenta um "caça-palavras" em que o aluno deve procurar as palavras dadas. Não reproduzimos aqui o quadro por entendermos que o comando da questão já é suficiente para a compreensáo dos objetivos e da metodologia implicados no uso do texto "O pato".

3 O LD apresenta anexo com alguns materiais destacáveis para realização de atividades de caráter mais lúdico. No caso específico, há uma folha com adesivos que reproduzem os versos da canção fora de ordem para que, na atividade, o aluno os organize, colando-os na página do LD. 
Conforme é possível observar, a proposta faz uso instrumental do poema-canção "O pato" ". Não há atividades direcionadas à leitura e compreensão do texto ou mesmo qualquer instrução ao professor para que trabalhe, antes de tudo, a leitura, a fruição, a percepção do caráter lúdico do poema, observável tanto no plano formal quanto no do conteúdo. Não há, sequer, a instrução para que ouçam ou cantem a canção, num aproveitamento mais autêntico desse objeto cultural em seu suporte enunciativo mais amplamente reconhecido.

Nesse sentido, é possível afirmar que atividades como essa, as quais são forte tendência nos LD analisados, fixam excessiva preocupação nos processos de decodificação. Deixam escapar excelentes oportunidades de lidar com a riqueza do texto literário em favor da formação do leitor a partir da sua vinculação com o ludismo próprio da literatura. Atuam diante do texto literário - e ensinam a criança a assim atuarem - como se aquele se tratasse de um conjunto de letras e palavras reunidas ao acaso, presentes ali apenas para o exercício do reconhecimento isolado dos grafemas e das possíveis combinações que formam palavras.

Mesmo em uma proposta um pouco mais complexa, de reorganizar os enunciados de cada verso para que perfaçam um texto (exercício 4), o que ocorre é a ativação de habilidades de identificação, comparação e reprodução a partir de índices grafológicos presentes no texto e nos adesivos. Isto é, a criança, para executar a atividade de ordenar os adesivos, precisa apenas identificar semelhanças entre as primeiras palavras - em alguns casos, as primeiras letras - de cada verso e, assim, reproduzir a ordem dada no texto base. Numa atividade como essa, pode-se afirmar que mesmo o procedimento da decodificação - a passagem de grafemas para sons e daí para sentidos - tem chances de ocorrer de forma muito restrita, o que nos permite considerar que não se trata de uma atividade de leitura nem de condução à formação leitora.

As atividades consideradas de leitura, isto é, que propóem, ao menos, a lida com habilidades que levem a processos de compreensão dos sentidos do texto, ainda que em sua estrutura mais superficial, foram quantificadas a partir de dois referenciais: leitura literal - superficial, com exercícios que lidam com

4 Optou-se por não reproduzir o poema, por tratar-se de obra amplamente divulgada. 
dados apenas textuais - e leitura literária - com reflexão mais profunda, que trabalha com a interação entre os elementos estéticos e temáticos da obra.

\begin{tabular}{|l|l|}
\hline Qualidade da atividade & Percentual nos LDs \\
\hline Leitura literal & $34 \%$ \\
\hline Leitura literária & $8,4 \%$ \\
\hline
\end{tabular}

Tabela 4: Percentual das propostas de leitura dos textos literários nos primeiros volumes das coleçôes.

Para melhor visualizar a situação da relevância dada à abordagem do texto literário nos $\mathrm{LD}$, é preciso retomar o processo de análise implementado na pesquisa, no qual foram realizados recortes diversos, criando-se subconjuntos. Assim, os textos que realizam atividade orientada para a leitura literária são um subconjunto do recorte de textos da tradição escrita presentes nos LD, que perfazem o subconjunto do recorte dos textos da esfera literária. Assim, em relação ao todo dos LD pesquisados, as atividades voltadas para a leitura literária são em torno de $2,37 \%$ da totalidade dos volumes do $1^{\circ}$ ano. Sendo esse índice o resultado de uma média realizada a partir dos dez livros estudados, em casos isolados, é possível encontrar até 7 atividades de leitura literária num único LD, ao mesmo tempo em que há livros cuja ocorrência de atividades de leitura literária é zero.

Também chama a atenção a tendência ao uso de metodologias desgastadas e questionáveis em seus resultados para a apreciação e compreensão do texto literário nos livros do $1^{\circ}$ ano. Entre as atividades de leitura, observa-se que $64,5 \%$ fazem uso de questionários, sendo boa parte deles com perguntas para respostas de múltipla escolha. Os 35,5\% restantes distribuem-se em atividades orais ou de produção de desenhos.

Um exemplo de atividade de leitura que pouco contribui para a formação do leitor foi observada no volume 1 do LD Português Linguagens: letramento e alfabetização. Vejamos:

Acompanhe a leitura que seu professor vai fazer deste poema: (Professor: Leia o poema enfatizando bastante o ritmo e a sonoridade criada pela repetiçáo dos fonemas $/ \mathrm{p} /, / \mathrm{R} / \mathrm{e} / \mathrm{s} /$.) 


\section{PASSARINHO APRESSADO}

(Professor: Sugerimos que, após sua leitura, apresente aos alunos a declamaçáo do poema, que se encontra no CD que acompanha o livro.)

De ramo em ramo,

Meio sem rumo,

Passa pulando

Pelo pessegueiro

Um passarinho.

No parque,

Ele passa

E pula e pia

E não para

Pra pegar

Um pêssego.

Que pressa é essa,

Passarinho?

Para um pouco

Pra prosear,

Passarinho.

Mas se não pode

Parar um pouco,

Que voe em paz

E pule sempre

E sempre pie,

Passarinho.

(Elias José. O jogo da fantasia. $3^{a}$ ed. São Paulo: Paulus, 2008, p. 22)

18. Um passarinho chegou ao parque, pulando e piando. Por que ele não para para pegar um pêssego? Marque a resposta com um X. 
(x) Porque tem pressa

( ) Porque está sem fome.

(Professor: Depois que os alunos responderem, lembre a eles que o título do poema é "Passarinho apressado".)

19. O poeta pede: "Pare um pouco pra prosear, passarinho".

a) $\mathrm{O}$ que quer dizer prosear? (Conversar)

b) O passarinho aceitou o convite? (Não)

20. No final do poema, o poeta diz:

"Que voe em paz

E pule sempre

E sempre pie,

Passarinho."

a) $\mathrm{O}$ poeta quer que alguma coisa de ruim aconteça ao passarinho? Por quê? (Não. Professor: Se necessário, lembre os alunos que a expressão "voar em paz" significa voar sem ser perturbado por ninguém.)

b) Você também gosta de ver os passarinhos voando, pulando e piando livremente? Por quê? (Resposta pessoal. Professor: O poema tem uma nítida mensagem ecológica. É importante aproveitar a oportunidade para conversar com os alunos sobre a importância de preservar o meio ambiente.)

(CEREJA, 2010, p. 159-160)

Conforme é possível observar, a atividade faz uso do tradicional questionário como forma de aferir ou conduzir o processo de compreensão leitora. Embora se trate de um poema com algumas possibilidades de interpretação, o LD opta por reduzir a leitura a mera atividade de identificação dos elementos que compóem a superfície textual, como ocorre nas questóes 18, 19 e 20a. Mesmo quando propóe alguma autonomia leitora, na questão $20 \mathrm{~b}$, de cunho pessoal, limita a possível interpretação à "doutrinação" ecológica.

O poema, ao nosso ver, embora composto por enunciados simples, traz, antes de uma mensagem ecológica, a expressão do sentido de liberdade. A imagem do pássaro solto na natureza, sua falta de rumo, seu desinteresse pelo prosaico alimento, o desejo do eu lírico pelo voo do animal constituem uma 
isotopia. Trata-se de um texto, portanto, com o qual a criança pode se identificar pelo que é próprio da infância: a falta de compromissos, a liberdade. Entretanto, a atividade não propóe uma leitura que conduza a tais sentidos, reduzindo, assim, a prática leitora a mero exercício de decodificação.

Vale ressaltar que, em se tratando de um poema com tal riqueza sonora (rimas internas, aliterações), surpreende a ausência de orientação do LD para o exercício de leitura em voz alta pela criança, o que promoveria a experimentação do aspecto formal do gênero, por meio da vivência lúdica, tão cara à literatura.

A realidade para os volumes do $2^{\circ}$ ano não é muito diversa da que se observou nos do $1^{\circ}$ ano. As atividades que fazem uso do texto literário como pretexto perfazem um total de $68,7 \%$ e distribuem-se da seguinte maneira:

\begin{tabular}{|l|l|}
\hline Objetivo da atividade & Percentual nos LDs \\
\hline Gramática & $29,5 \%$ \\
\hline Caracterização de gênero & $17,6 \%$ \\
\hline Produção textual & $9,1 \%$ \\
\hline Reflexão temática & $12,5 \%$ \\
\hline
\end{tabular}

Tabela 5: Percentual de propostas com instrumentalização dos textos literários nos segundos volumes das coleçôes didáticas.

Já as atividades de leitura, num total de 31,3\% distribuem-se em:

\begin{tabular}{|l|l|}
\hline Qualidade da atividade & Percentual nos LDs \\
\hline Leitura literal & 22,7 \\
\hline Leitura literária & 8,5 \\
\hline
\end{tabular}

Tabela 7: Percentual das propostas de leitura nos segundos volumes das coleçóes.

Novamente, o índice de atividades dedicadas à leitura literária, em relação à totalidade dos LDs, é bastante baixo, somando apenas 2,6\%.

No que se refere ao tipo de atividade, ocorre um agravamento da situação vista no $1^{\circ}$ ano: os questionários somam $76 \%$ das propostas de trabalho com a leitura literária, enquanto os demais tipos de abordagem ficam reduzidos a $24 \%$. 
Uma hipótese para esse superdimensionamento dos questionários no $2^{\circ}$ ano seria a expectativa num maior domínio do código por parte dos alunos e a consequente autonomia em relação ao uso do LD. De todo modo, vale ressaltar que o investimento no questionário enquanto guia principal das atividades de leitura conduz a uma relação individual e isolada do estudante com o texto, minimizando e, por vezes, impedindo a formação de comunidades leitoras, cuja condição essencial é o compartilhamento das interpretações.

As poucas ocasióes em que foram identificadas propostas de leitura compartilhada, na qual os alunos são autorizados a trocar com os colegas impressôes a respeito do texto lido, observou-se a ineficácia da atividade, na medida em que mantém-se fixada à superfície do texto. $\mathrm{O}$ exemplo a seguir evidencia esse tipo de ocorrência:

O autor Elias José utilizou a ideia dos classificados para criar um poema. Veja como ele fez.

Coisas dispensáveis

Quem quiser comprar eu vendo:

um gato que deixa o rato sossegado

uma vaca que só berra em shopping

um gnomo que foge da floresta

uma borboleta que só fica parada

um palhaço que chora e faz chorar

um mágico desligado dos sonhos e fantasias

um sapo que se recusou a virar príncipe

um príncipe que sonha em ser sapo

uma princesa que se nega a entrar na história

um passarinho que detesta cantigas e cantores

uma feiticeira boa que vive dando conselhos

um mocinho de cinema que não anda a cavalo.

Eu vendo, troco, empresto, dou.

pois não servem mesmo pra nada!

Elias José, Um jeito bom de brincar. São Paulo: FTD, 2002. p. 9 


\section{DISPENSÁVEL: DESNECESSÁRIO, QUE NÁO FAZ FALTA. $^{5}$}

1. O texto fala de seres que alguém não quer mais. Por que eles foram considerados dispensáveis? (Porque, de acordo com o texto, não fazem o que se espera que façam. Por exemplo: gato deve caçar rato, borboleta deve voar.)

2. Converse com os seus colegas:

a) Qual é o problema com o gato? ( $\mathrm{O}$ gato não caça os ratos, ele os deixa sossegados.)

b) $\mathrm{O}$ que acontece com a princesa? (Ela não quer entrar na história.)

c) Que nome você daria a uma feiticeira boa? (Sugestão: fada.) (PRADO; HULE, 2011, p. 42,43)

O poema de Elias José joga em pelo menos duas vertentes de sentidos. Uma delas, mais evidente, refere-se à falta de disposição dos diversos elementos do mundo encantado para assumir os lugares a eles designados. Todos eles não se dispôem a assumir os clichês que envolvem suas figuras. Todos eles se indispóem de sua condição. Parecem, nesse sentido, muito próximos a um universo nada mágico, onde a frustração é elemento típico da experiência humana. Outra possibilidade de leitura, coerente com esta primeira, é a percepção da contrariedade do eu lírico, que se ressente diante da perda do encanto dos objetos que possui.

Vê-se, portanto, que, apesar de se expressar por meio de uma linguagem simples, o poema toca em questóes existenciais profundas que, no entanto, podem ser percebidas e comentadas pelas crianças, na medida em que se revestem de um imaginário que as atinge muito facilmente - animais humanizados, fadas, palhaços, mágicos etc. Mais que identificar a inutilidade dos elementos citados no texto, como propóe a atividade, seria interessante, enquanto exercício de leitura, discutir por que tais figuras não desejam mais esses lugares. Mais ainda, refletir por que esses elementos, originalmente sem utilidade para uma vida prática (à exceção do gato caçador), fazem falta ao eu lírico quando destituídos de suas características primordiais.

5 Na página do LD, há inserção de vocabulário auxiliar, nesse caso, restrito a uma só ocorrência. 
É certo que uma reflexão assim complexa a respeito da utilidade daquilo que, num mundo regido pelo utilitarismo nas relações, é inútil, só poderia ser implementada por meio de um diálogo conduzido pelo professor, que organizaria as participações dos alunos na direção de um compartilhamento de ideias e de interpretaçóes.

A proposta de leitura do LD, no entanto, ao orientar o trabalho de compartilhamento entre os alunos, reduz a atividade a uma tarefa de busca de elementos superficiais, literais, que não demandam interlocução e intersubjetividade. Isto é, faz uso burocrático apenas de uma estratégia que, quando bem realizada, tem condiçóes de instaurar uma verdadeira comunidade leitora, conjuntura fundamental para a formação do leitor.

\section{Considerações finais}

A pesquisa com coleçóes didáticas do $1^{\circ}$ e $2^{\circ}$ anos do Ensino Fundamental teve como perspectiva observar o quanto de uma realidade já amplamente criticada ainda persiste no Brasil.

A primeira fase das investigaçóes revelou que os livros didáticos aprovados pelo PNLD apresentam uma quantidade relativamente equilibrada entre os textos da esfera literária e os da esfera do cotidiano, o que pode conduzir a uma interpretação equivocada de que o texto literário é suficientemente trabalhado nas séries inicias do Ensino Básico.

Num exame mais detalhado, foi possível concluir que, embora haja uma quantidade grande de textos da esfera literária, o modo de abordá-los ainda persiste na apropriação dos mesmos como pretexto para o desenvolvimento de habilidades que não promovem a efetiva formação do leitor ou do apreciador de literatura.

Confrontadas com as demais atividades, as propostas de leitura do texto literário são uma fatia irrisória do conteúdo presente nos LD analisados. Essa realidade, em si, já seria suficiente para considerar que o trabalho com a leitura não vem sendo realizado de maneira profícua, na medida em que centra o foco do ensino em produçóes discursivas que visam à "adaptação do homem ao meio” - os gêneros do cotidiano - conforme critica Ortega y Gasset (1993). Igualmente, não promovem processos de humanização - tarefa primordial da escola enquanto instituiçáo difusora da cultura -, na medida em que limitam 
o acesso ao texto literário a uns poucos exemplos, muitas das vezes adaptados ou mutilados.

Adensando esse fato, quando há espaço para a exploração da leitura do texto literário, pode-se verificar que persistem, quase trinta anos depois, os "exercícios de copiação" apontados por Marcuschi (1996) - como visto na primeira atividade analisada - e a subvalorização do texto, como denuncia Pinheiro (2005) - observada na segunda análise.

Outrossim, as propostas de leitura, mesmo as mais interessantes do ponto de vista da interpretação e da produção de sentidos por meio de abordagens que tendem a explorar mais as possibilidades subjetivas na interação do leitor com o texto, ainda pressupõem um leitor isolado. Isto é, não se encontram nos $\mathrm{LD}$ analisados atividades que promovam o compartilhamento das interpretações e a consequente formação de comunidades leitoras, afinal, não instigam o diálogo entre os leitores e entre suas interpretaçóes.

É preciso relembrar que a formação do leitor deve ser um processo a ser desenvolvido ao longo de todo o período de escolarização e mesmo após ela. Ao Ciclo 1 do Ensino Fundamental cabe o papel de instauração desse percurso, o qual deverá ser tanto melhor quanto mais seguro e investido de significado. A literatura, conforme afirma Candido (1995), dispóe de um potencial temático e estético que vincula o sujeito, na medida em que se percebe ali representado. Nessa esteira, a literatura permite o exercício da imaginação, do qual, segundo Ortega y Gasset (1993), uma educação libertária jamais poderá prescindir. Deste modo, abdicar da leitura literária já nos primeiros anos da educação formal significa também renunciar à formação de um cidadão criativo, disposto a alterar as realidades e a participar da construção de novos caminhos para a sociedade.

O LD, "primo rico" das editoras, dada a proporção que tomou a partir da expansão da política do PNLD, tem fortalecido uma situação de destituição do lugar da docência. Na medida em que difundem práticas e metodologias que não consideram a autonomia do professor como elemento fundamental para o ensino da leitura, os LD disseminam o que Geraldi (2015) denominou "exercício da capatazia”. Preenchendo os hiatos estabelecidos pela má qualidade da formação docente no Brasil, instauram um processo de difusão de metodologias e de toda uma ideologia que manifesta a opção pela criação de leitores precários, alvos fáceis das manipulaçóes discursivas de que se favore- 
cem os mesmos grupos que enfatizam tais políticas em lugar do investimento nos currículos da formação docente. Grupos para os quais o leitor criativo, capaz de imaginar uma realidade diversa daquela que o oprime, significa um risco a ser combatido.

Antes de concluir, deve-se salientar, porém, que a política de distribuição de livros didáticos e de objetos de leitura, principalmente em certas localidades mais distantes, onde os resultados de uma formação docente de qualidade tendem a chegar mais tardiamente, não é de todo ruim ou equivocada. Entretanto, parece-nos urgente rever os pressupostos que viabilizam a distribuição de materiais cuja qualidade mostra-se questionável do ponto de vista da formação do leitor. E, por outro lado, vale ressaltar a necessidade de uma revisão dos argumentos teóricos e mesmo ideológicos que têm matriciado boa parte da produção metodológica do ensino de leitura para um campo em que se exila qualquer possibilidade de criticidade, criatividade e subjetividade.

\section{Referências}

BETTELHEIM, B e ZELAN, K. Aprender a leer. Barcelona: Crítica, 2009.

BRASIL. Guia de livros didáticos: PNLD 2013: letramento e alfabetização e língua portuguesa. - Brasília : Ministério da Educação, Secretaria de Educação Básica, 2012.

CÂNDIDO, Antonio. Vários escritos. São Paulo: Duas Cidades, 1995.

CEREJA, Willian Roberto; MAGALHÃES, Thereza Cochar. Português: linguagens. 3. ed. São Paulo: Atual, 2010.

COLOMER, Teresa. Andar entre livros: a leitura literária na escola. Tradução de Laura Sandroni. São Paulo: Global, 2007.

GERALDI, João Wanderley. A aula como acontecimento. São Carlos: Pedro e João Editores, 2015.

LAJOLO, Marisa; ZILBERMAN, Regina. A formação da leitura no Brasil. São Paulo: Ática, 1999.

MARCUSCHI, Luís Antônio. Exercícios de compreensão ou de copiação nos manuais de ensino de língua. Em aberto, ano 16, n.69, Brasília. p. 64-82.jan/ mar. 1996,

ORTEGA Y GASSET, José. El Quijote en la escuela. Revista da Faculdade de Educação. v.19, n.1, p.11-38, São Paulo, jan/jun.1993. 
PINHEIRO, José Helder. Abordagem do poema: roteiro de um desencontro In: DIONÍSIO, Ângela Paiva e BEZERRA, Maria Auxiliadora. O livro didático de português: múltiplos olhares. Rio de Janeiro: Lucerna, 2005, p. 62-74.

PRADO, Angélica e HULE, Cristina. Projeto prosa: língua portuguesa. $1^{\circ}$ ano. São Paulo: Saraiva, 2011.

TORRES, Ana Paula Dias e BORIO, Maria Aparecida. Lingua portuguesa. São Paulo: Brasiliana, 2008.

\title{
LITERATY READING IN CYCLE 1 OF BASIC EDUCATION: THE TEXTBOOK AS TRIGGERING ELEMENT FOR WEAK READERS
}

\begin{abstract}
The policy for the reader's formation in Brazil accounts, among others, the distribution of textbooks in mother tongue for public schools across the country. Such materials have reading methodological approaches ineffective for the reader's formation in its early stages, as shown by study carried out between 2013 and 2015 with the first two volumes of ten didactic collections of Portuguese.
\end{abstract}

KEYWORDS: reading; literature; textbooks.

Recebido em: 30/10/2015

Aprovado em: 25/01/2016 